\title{
The Role of Social Security in Respecting and Protecting the Dignity of Lone Mothers in South Africa: Summary of Findings and Recommendations
}

This study explored lone mothers' experiences of social security in South Africa in terms of whether it protects and respects their dignity. Interviews were undertaken with almost two hundred low income lone mothers and the impact on dignity was examined. Interviews were also held with senior policy makers in government, and social attitudes were explored more broadly in relation to dignity, poverty and social security using data from the South African Social Attitudes Survey.

\section{Key points}

- Dignity is a foundational value in South Africa's Constitution and was described as very important by the focus group participants. Examples of dignity 'in practice' include being valued, respected, able to fulfil important roles in life, and able to provide for oneself and others.

- Many examples were provided of ways in which poverty erodes dignity.

- The Child Support Grant (CSG) was found to be helpful in protecting dignity as it is a contribution to the cost of raising a child. However many women reported ways in which the CSG is detrimental to their sense of dignity including issues with the application process, negative attitudes towards them as CSG recipients within their communities, and the small amount of the grant which does not adequately cover the needs of a child.

- Overall the CSG was seen as an expression of social solidarity or Ubuntu.

- Many participants stressed the need for jobs but in the absence of sufficient employment opportunities there was strong support for the idea of providing social grants to caregivers, as currently working age caregivers are only entitled to social assistance if they are disabled.

The research

By Gemma Wright, Michael Noble, Phakama

Ntshongwana, David Neves and Helen Barnes.

A collaboration between the Centre for the Analysis

of South African Social Policy at the University of

Oxford, the Institute for Poverty, Land and Agrarian

Studies at the University of the Western Cape, and

the Human Sciences Research Council.
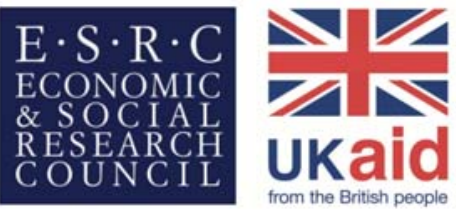

Research jointly supported by the ESRC and DFID 


\section{BACKGROUND}

\section{The South African Constitution states that 'Everyone has inherent dignity and the right to have their dignity respected and protected'. How is dignity experienced by lone mothers in South Africa in practice? And what role does social security play in respecting and protecting their dignity?}

\section{Methodology}

Thirty-six focus groups and 16 in-depth interviews were undertaken in the Eastern Cape and Western Cape in South Africa with low income female caregivers. Just under 200 women took part in the focus groups. Interviews were also held with senior policy makers in government, and social attitudes were explored more broadly in relation to dignity, poverty and social security using data from the HSRC's South African Social Attitudes Survey.

\section{Main findings}

Although there are complex and subtle messages to be found within this study, ten key findings are highlighted here:

- Lone mothers face multiple challenges and yet are often neglected in the policy arena. Lone mothers fall outside the scope of social assistance in South Africa as there is no provision for adults unless they are disabled or aged 60 or above.

- As well as being a foundational value in South Africa's Constitution, dignity was understood and experienced as being a very important concept, not only by the low income lone mothers who participated in the qualitative research, but also by a nationally representative sample of all South African adults as evidenced by analysis of a module on dignity in the South African Social Attitudes Survey.

- The main reason why lone mother respondents said that their dignity should be protected and respected was because of their roles as caregivers: they take this role extremely seriously.

- Poverty was described by lone mothers as erosive of their dignity. It impacted negatively on their sense of self-esteem, worthiness, autonomy, and self-respect. Many of the methods and strategies of surviving poverty were also described by lone mothers as being detrimental to their sense of dignity, particularly begging, demeaning work for family and neighbours, tolerating precarious employment, and transactional sex.

- The elite interviewees (senior policy makers) stressed that dignity plays an important role in social security policy design, and that its purpose is to help to protect people's dignity by providing an income to alleviate poverty. Notwithstanding this, several examples were given where the policy design could inadvertently compromise dignity, including the CSG meanstest, and the exclusion of caregivers from social assistance. 
- The CSG plays multiple roles in relation to dignity which are both general and contextspecific. It plays a vital role in helping lone mothers to provide for their children, yet was also perceived by many as being so small an amount as to have little impact on the protection of their dignity as caregivers. The process of applying for CSG was described by many as being detrimental to dignity, as was the opprobrium often associated with their status as CSG recipients. Nevertheless, as demonstrated by the in-depth interviews in particular, the use of the CSG as an income stream contributed positively and in dignity-enhancing ways to the lives of many of the informants.

- Decent paid work was regarded by lone mothers as the main route to attaining dignity.

- In the absence of sufficient employment opportunities, there was strong support for the introduction of a form of social security for lone mothers, both amongst the participants in the focus groups and more broadly within the social attitudes survey.

- There was a widespread appreciation amongst focus group participants, and respondents to the social attitudes survey, of the provision of formal social security by the state being a manifestation of social solidarity. Notwithstanding this, dignity-eroding aspects of the administration of the CSG by some officials, and the opprobrium accorded to CSG recipients, meant that for many lone mothers any experience of the spirit of social solidarity was elusive.

- Social support, whether from state or family, plays a vital role for low income people, and yet it is not always positively experienced. Negative aspects of both state-provided social security and traditional forms of social support were highlighted. Whilst state support was regarded as preferable, in principle, to dependence on other (usually just as poor or only slightly less so) family members, paid employment was regarded by lone mothers as being far and above the optimal way in which to protect and respect dignity.

\section{Recommendations}

\section{Extend social security provision}

In parallel with job creation schemes and affordable high quality childcare, social security provision should be extended to include low income adults of working age, regardless of caregiver status. This would be consistent with the constitutional commitment to achieve the progressive realisation of access to social security including social assistance for people and their dependants who are unable to support themselves. Extending social security would also be advantageous from a child rights perspective: as the CSG is of necessity diluted across other family members, it cannot be expected that child poverty could ever be eliminated if the needs of the family in which children live are not also addressed. Furthermore, the care that the children receive cannot be expected to be of high quality if the caregiver cannot meet her or his own material needs. Social security provision for impoverished caregivers with young children should not be linked to an obligation to seek work as they should be entitled to choose whether to undertake paid work or do the unpaid work of looking after their child or children, or some combination thereof. 


\section{Recognise poverty and inequality as threats to human dignity}

The study revealed many ways in which poverty and inequality are detrimental to people's dignity. Furthermore, many of the strategies that women used to survive poverty were also experienced as detrimental to dignity. Policy responses ought to include interventions to create additional employment opportunities and affordable childcare provision. However, again it should be recognised that caregivers' responsibilities, as a contribution to society, may be at odds with paid employment and their choices should be respected and supported through the social security system.

\section{Challenge the false dichotomy of independent self-upliftment versus passive social grant receipt}

The false dichotomy of independent self-upliftment versus passive social grant receipt needs to be challenged, especially in the popular imaginary. Not only is the notion of passive grant receipt unsupported by the evidence, but it is a formulation that is erosive of recipients' dignity. Some of this reframing would entail emphasising the prevalence and value of unpaid carework. It is work that is intensely gendered and often invisible, yet crucial to their dependants and society in general. Moreover social grant receipt is frequently combined with repertoires of productive and income-generating activities. Much of the discourse valorising 'independent self upliftment' overlooks both these facts, and the hard realities of a paucity of employment opportunities for unskilled South Africans.

\section{Acknowledge and deal with stigma and the discourse of dependency}

Much of the popular (and even on occasion official) discourse concerning social security is marked by censure and opprobrium and serves to perpetuate stigma. Such discourses can be challenged with evidence: (i) everyone depends on others, but what differs is the conditions under which people are dependent; (ii) there is no evidence that people out of work have markedly different attitudes to work from those in work; (iii) caregiving is actually work and should be valued as such; and (iv) rather than prioritising a ruthless 'sink or swim' ethos, the Constitution commits to a range of socio-economic rights which are hard fought-for social rights of citizenship. Aspects of this debate could also be located within the notion of social solidarity, and Ubuntu. This would entail disputing the fallacious notion that state and informal social support are in opposition, by instead underscoring the commonalities and synergies between them. Promotion of the notion of social solidarity inherent in redistributive social security systems would better serve to protect the dignity of recipients.

\section{Improve the design and implementation of the CSG}

The CSG plays a vital role in the lives of low income families, and its positive impacts have been well documented elsewhere. There are a number of ways in which it could be further improved in order to maximise its ability to protect and respect the dignity of recipients. The application process was described by many as detrimental to their dignity, with the main issues being the burdensome nature of the process and the manner in which they were often treated. It is recommended that:

- Efforts should be made to raise public awareness about the eligibility criteria (especially supporting documentation required) for CSG applications;

- Queues at the application offices should be kept to a minimum and appropriately managed;

- Training and supervisory oversight should be stepped up to ensure that applicants are treated with dignity. 
Lastly, in relation to the CSG, it is recommended that:

- The CSG means test should be removed (universalisation of the grant).

There are many well-rehearsed reasons why the removal of the means-test would be advantageous for the promotion of CSG take-up and consequent reduction of child poverty and investment in child development. In the context of this study, universalisation of the CSG is advocated as it would remove at a stroke any association with the caregiver's income or employment status. The CSG would then cease to emblematic of the caregiver's poverty status, and so would become less erosive of dignity. The CSG would only reflect the fact of there being a child in the household.

\section{Conclusion}

As well as being a constitutional right this study revealed that dignity is vitally important to people in South Africa in the context of their daily lives. It was demonstrated that poverty impacts negatively on dignity. Although the CSG helped lone mothers fulfil their role as caregivers and was used in dignity-enhancing ways, it was felt by many to be inadequate and aspects of the application process and the stigma associated with receipt were experienced as erosive of dignity. Comprehensive social security, if implemented in a way that promotes social solidarity and is sensitive to the dignity of applicants, could play an important role in helping to protect and respect people's dignity.

\section{About the project}

A group of researchers from the Centre for the Analysis of South African Social Policy at the University of Oxford in the UK, the Institute for Poverty, Land and Agrarian Studies at the University of the Western Cape in South Africa, and the South African Human Sciences Research Council undertook a research project between 2011 and 2014 entitled 'Lone Mothers in South Africa - The role of social security in respecting and protecting dignity'. It was funded by the Economic and Social Research Council and the UK Department for International Development (ESRC Ref ES/I033130/1).

\section{For further information}

- Policy Brief 1: Poverty erodes dignity: perspectives of low income female caregivers in South Africa

- Policy Brief 2: South Africa's Child Support Grant and the dignity of female caregivers

The full report, The Role of Social Security in Respecting and Protecting the Dignity of Lone Mothers in South Africa: Final Report by Gemma Wright, Michael Noble, Phakama Ntshongwana, David Neves and Helen Barnes, is available at http://www.casasp.ox.ac.uk/docs/Dignity final report 120714.pdf. Or for further information contact Dr Gemma Wright by email gemma.wright@saspri.org or phone +27 (0)21 8136435 . 